\title{
Corrigendum
}

\section{AMBRA1 is able to induce mitophagy via LC3 binding, regardless of PARKIN and p62/SQSTM1}

\author{
F Strappazzon, F Nazio, M Corrado, V Cianfanelli, A Romagnoli, GM Fimia, S Campello, R Nardacci, M Piacentini, M Campanella \\ and $\mathrm{F}$ Cecconi
}

Cell Death and Differentiation (2015) 22, 517; doi:10.1038/cdd.2014.190

Correction to: Cell Death and Differentiation (2015) 22, 419-432; doi:10.1038/cdd.2014.139; published online 12 September 2014

Since the publication of this paper the authors have noted an omission from the acknowledgements section.

The corrected Acknowledgements is shown below and the corrected paper appears in this issue together with this corrigendum. The authors would like to apologize for any inconvenience this may have caused.

\section{Acknowledgements}

We thank Mrs M Acuña Villa and Dr M Bennett for secretarial and proofreading work and $A$ Di Rita for research assistance. We are indebted to Professor B Levine (Dallas, TX, USA) for kindly providing us with the Bcl-2-ActA construct. We acknowledge Professor J Shen (Boston, MA, USA) who provided Pink1/mice and Dr. $\mathrm{P}$ Bonsi from Professor A. Pisani's lab (Rome, Italy) for her help in breeding these mice. The cell line from patients affected by Parkinson's disease were obtained from the 'Cell Line and DNA Biobank from Patients affected by Genetic Diseases' (Istituto G. Gaslini) and the 'Parkinson Institute Biobank' (Milan, http://www.parkinsonbiobank.com/), members of the Telethon Network of Genetic Biobanks ((http://www. biobanknetwork.org, project no. GTB12001), funded by Telethon Italy. This work was supported in part by grants from the Telethon Foundation (GGP10225), AIRC (IG2010 to FC and MyFAG 2009 to SC), FISM (2009), the Italian Ministry of University and Research (PRIN 2009 and FIRB Accordi di Programma 2011), the Italian Ministry of Health (Ricerca Finalizzata and Ricerca Corrente to FC, Ricerca Finalizzata-Progetto Giovani Ricercatori to SC) and Ricerca Finalizzata RF-OGR-2008-120-3614 to MP. 